\title{
Symptoms and health status before and six weeks after open cholecystectomy: a European cohort study
}

\author{
N A Black, E Thompson, C F B Sanderson, and the ECHSS group
}

\begin{abstract}
The impact of open cholecystectomy on patients' symptoms and health status and their level of satisfaction has been examined to provide a basis for comparison with newer rival treatments. A prospective cohort study using patient and surgeon completed questionnaires before and six weeks after surgery was carried out in 14 general hospitals in eight European countries. Five hundred and eighty three patients were recruited consecutively in 1990 to 1991 . Information on their symptoms, general health status, activities of daily living, and satisfaction with their care were collected. After surgery $42.8 \%$ of patients reported that they were free of symptoms. Symptoms varied in their responsiveness to surgery six weeks after surgery $89 \%$ of those who had complained of vomiting had improved, $81 \%$ of nausea, $69 \%$ of loss of appetite, $65 \%$ of abdominal pain, and $51 \%$ of flatulence. In contrast $28 \cdot 1 \%$ of patients still suffered from flatulence and $23.5 \%$ continued to complain of abdominal pain. Most patients' (62.7\%) general health improved, 28\% were unchanged, and 9.3\% were worse. After surgery most patients reported no restrictions in their normal social activities (75-90\% depending on the activity) and most $(89.5 \%)$ felt the results of their operation had been as expected or better than expected. Most patients undergoing open cholecystectomy reported an improvement in their symptoms, health status, and social functioning. This was reflected in their high level of satisfaction. Some patients, however, gained no benefit and a small proportion were worse than before surgery.
\end{abstract}

(Gut 1994; 35: 1301-1305)

Department of Public

Health and Policy,

London School of

Hygiene and Tropical

Medicine, London

N A Black

E Thompson

C F B Sanderson

The ECHSS group

Correspondence to: Dr N A Black, Health Services Research Unit Department of Public Health and Policy, London School of Hygiene and Tropical Medicine Kepel Street, London WC1E 7HT.

Accepted for publication 21 December 1993

Although open cholecystectomy is rapidly being replaced by other treatments, most dramatically by a laparoscopic approach, it has been the preferred treatment for gall bladder disease throughout this century. ${ }^{1}$ The need for comprehensive, accurate data on open cholecystectomy has increased (rather than decreased) in recent years with the introduction of the laparoscopic approach. This is because, as the 1992 US National Institute of Health consensus statement on laparoscopic cholecystectomy recognised, there is little prospect of adequate randomised trials comparing the two procedures being conducted. ${ }^{2}$ They also recognised the 'paucity of long-term outcome data even for traditional procedures'.

Open cholecystectomy is performed to reduce symptoms and improve health status and quality of life. Most studies of symptom change have been retrospective reviews of individual surgeons' case series and have reported widely differing proportions $(50-88 \%)$ of patients obtaining symptomatic cures. ${ }^{3-5}$ While some of the patients who still had symptoms reported only mild problems, between $2 \%$ and $32 \%$ reported severe symptoms. Such wide differences reflect variation in the types and severity of patients included in the studies, different definitions and methods of measuring symptoms, and how long after surgery they were assessed. Early studies suggested that while most symptoms recurred within one year of surgery, the prevalence continued to increase over several years. ${ }^{3}$ More recent prospective studies have found that in about half the patients who suffer postoperative symptoms, the symptoms recur immediately ${ }^{6}$ and there is little change in symptom prevalence after the third postoperative month. 78

If our knowledge of the symptomatic outcome of open cholecystectomy is poor, then evidence about the impact of the operation on health status, activities of daily living, and patient satisfaction is even worse. Only two studies have measured the general health status of patients before and after surgery. 89 Both used the Nottingham Health Profile and reported significant improvements in four of the six dimensions (pain; emotional reactions; energy; sleep). These benefits occurred within 5-12 weeks of the operation and persisted for at least a year. A trial of minilaparotomy cholecystectomy against laparoscopic has also shown that patients' general health status improved significantly within one month. ${ }^{10}$

An early attempt to assess the activities of daily living that postsurgical patients could undertake found that $96 \%$ had resumed their normal activities one to two years later. ${ }^{11}$ It was subsequently found in another study, however, that in the shorter term the results were not so impressive - only $38 \%$ had resumed normal activities within six weeks. ${ }^{12}$ More recently a study in the USA showed that patients gained only 
slight improvement in functional status - more than that after prostatectomy but much less than after coronary artery surgery or total hip replacement. ${ }^{13}$

Finally, two American studies have found that most patients are satisfied with their treatment: in one, $97 \%$ rated their medical care as good or excellent and $90 \%$ their length of hospital stay as appropriate ${ }^{11}$; in the other, patients were very satisfied with their overall care. ${ }^{13}$ In two other studies, however, only about half the patients rated their operation as completely successful. ${ }^{612}$ These findings may reflect patients having false expectations as to the possible benefits of cholecystectomy. This, in turn, may reflect a comparative lack of knowledge about symptomatic and health status outcomes after this operation. This study seeks to throw light on this.

The objectives of this paper are: to describe the preoperative symptoms and health status of patients undergoing open cholecystectomy in typical general hospitals in Europe; to assess the change in these measures six weeks after surgery; and to determine the level of patient satisfaction with their care.

\section{Methods}

The study was set up by the European Collaborative Health Services Study (ECHSS) group of the Association of Schools of Public Health in the European Region (ASPHER). The ECHSS, an international group of health services researchers, had carried out similar studies in the past. ${ }^{14}$ The study required one or two hospitals in each country to participate. To ensure some similarity of case mix, they had to be general hospitals in towns or suburbs rather than major city centres. The project leader (CS) and coordinator (ET) identified five members of the ECHSS who wished to participate (UK, Ireland, Portugal, The Netherlands, Sweden). Researchers in four other countries (Germany, Spain, Italy, France) were recruited by the project leader. The study was designed during a two day meeting in Brussels attended by a surgeon and a researcher from each participating country.

During 1990/91 each of the 16 participating hospitals was expected to recruit 50 consecutive patients so as to permit meaningful interhospital comparisons to be made. In

TABLE I Preoperative symptoms reported by patients $(n=583)$ and surgeons $(n=570)$ (proportions based on the number for whom information was available)

\begin{tabular}{llll}
\hline & \multicolumn{2}{l}{ Patients' reports } & \\
\cline { 2 - 3 } Symptom & In past 6 months & In past 7 days & $\begin{array}{c}\text { Surgeons' reports } \\
\text { in past } 7 \text { days }\end{array}$ \\
\hline Abdominal pain & $441(75 \cdot 6)$ & $342(60 \cdot 0)$ & $338(59 \cdot 3)$ \\
Nausea & $315(54 \cdot 0)$ & $236(41 \cdot 4)$ & $262(46 \cdot 0)$ \\
Vomiting & $243(41 \cdot 7)$ & $172(30 \cdot 2)$ & $171(30 \cdot 0)$ \\
Jaundice & $69(11 \cdot 8)$ & $67(11 \cdot 8)$ & $59(10 \cdot 4)$ \\
Loss of appetite & $212(36 \cdot 4)$ & $205(36 \cdot 0)$ & NA \\
Flatulence & $334(57 \cdot 3)$ & $281(49 \cdot 3)$ & $228(40 \cdot 0)$ \\
Fever & $117(20 \cdot 1)$ & $98(17 \cdot 2)$ & $81(14 \cdot 2)^{\star}$ \\
Heartburn & NA & NA & $108(18 \cdot 9)$ \\
Fat intolerance & NA & NA & $283(49 \cdot 6)$ \\
\hline
\end{tabular}

$\mathrm{NA}=$ not available. ${ }^{\star}$ Refers to rigors; surgeons also reported that $28(4.9)$ patients had a history of a fever $>39^{\circ} \mathrm{C}$, and $166(29 \cdot 1)$ had experienced a fever $37-39^{\circ} \mathrm{C}$. practice, two hospitals failed to complete the study, leaving 14 hospitals that recruited 613 patients of which 583 were open operations. Patients became eligible for the study at the time the decision to carry out a cholecystectomy was made.

Data were collected both from the patients and the hospital staff. Patients were asked to complete a questionnaire after admission to hospital but before surgery. The questionnaire covered their symptoms both over the preceding six months and one week before admission, general health status, comorbidity, expectations of surgery, social functioning, use of domiciliary services, and sociodemographic characteristics. They were also asked to complete a mailed questionnaire about six weeks after their operation. This covered most of the factors included in the preoperative questionnaire plus questions about their postoperative recovery and their satisfaction with their treatment.

Surgeons were asked to complete a preoperative questionnaire, which covered the patient's symptoms and signs, comorbidity, investigations and the reason for operating. Information was also collected during the patient's stay in hospital from the doctors and nurses responsible for their care. Details were collected of the operation (preoperative treatment, anaesthesia, type of operation, surgeon's experience, length of operation, findings), the postoperative care (contacts with staff, investigations, treatments, progress), and postoperative complications. Surgeons were asked to see all the patients four to six weeks after the operation and to record details of symptoms, results of investigations, further treatments, and a final diagnosis.

The questionnaires were designed during a second two day meeting in Brussels, similar in composition to the previous one. The questionnaires were translated into each relevant language and then translated back by someone else to detect any errors. They were then piloted in each participating hospital. During and after the piloting (in early 1990) the coordinator visited each hospital to discuss data collection methods and any problems that had arisen. The questionnaires were subsequently revised and retranslated.

By completing a preoperative questionnaire, a patient entered the study $(n=583)$. Later reviews of the work of the hospitals during their recruitment periods showed most eligible patients had been entered into the study. No patient refused to participate, so that failure to recruit resulted from oversight by clinical staff. Recruitment periods varied between hospitals from seven weeks to one year, partly reflecting differences in the volume of cholecystectomies performed and partly the level of interest of the participating surgeons. The number of patients recruited by each hospital therefore varied widely from 10 to 100 . Most hospitals (10) recruited a patient to the study every four to seven days.

Completed preoperative surgeon questionnaires were obtained for $570(98 \%)$ patients. Postoperative questionnaires were received 
TABLE II Patients' perceptions of their general health over the previous two weeks

\begin{tabular}{lcc}
\hline & Preoperative $(n=583)$ & Preoperative $(n=486)$ \\
\hline Poor & $106(18 \cdot 2)$ & $20(4 \cdot 1)$ \\
Fair & $242(41 \cdot 5)$ & $76(15 \cdot 6)$ \\
Good & $147(25 \cdot 2)$ & $197(40 \cdot 5)$ \\
Very good & $47(8 \cdot 1)$ & $137(28 \cdot 2)$ \\
Excellent & $16(2 \cdot 7)$ & $52(10 \cdot 7)$ \\
Not known & $25(4 \cdot 3)$ & $4(0 \cdot 8)$ \\
\hline
\end{tabular}

from $486(83 \%)$ patients despite no reminders being sent. Non-responders were similar to responders as regards age, sex, and diagnosis but were more likely to have completed their fulltime education before 19 years of age, though this difference was not statistically significant $(94 \%$ v $83 \%, \mathrm{p}=0.06)$. Completed questionnaires from hospital staff on the patient's hospital stay were obtained for 566 (97\%) and on follow up for $559(96 \%)$ patients. A large proportion $(237,41 \%)$ were followed up five to seven weeks after surgery. Of the remainder, $64(11 \%)$ were seen sooner while $115(20 \%)$ were not seen until 8-10 weeks after surgery and $95(16 \%)$ not until more than 10 weeks. The time to follow up was not known for $71(12 \%)$ patients. Completed questionnaires from each participating hospital were sent to the project coordinator in London for coding, data entry, and analysis.

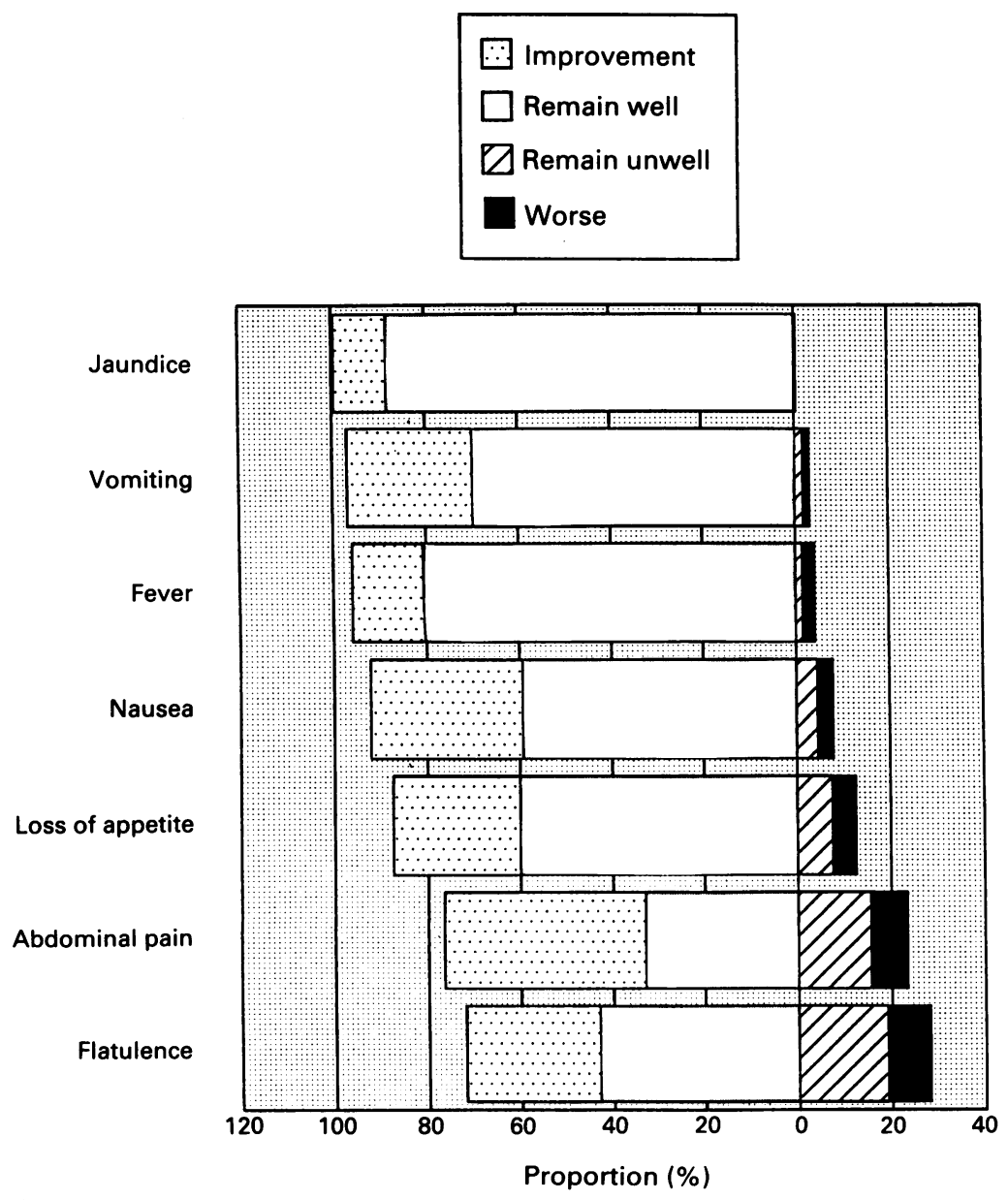

Figure 1: Proportions of patients reporting improvement, remaining well, remaining unwell, and worsening of symptoms compared with their health during the week before surgery $(n=468)$.

\section{Results}

PREOPERATIVE SYMPTOMS AND HEALTH STATUS Most patients $(75 \cdot 6 \%)$ reported suffering abdominal pain during the preceding six months (Table I). The next most common symptoms were flatulence $(57 \cdot 3 \%)$, nausea $(54 \cdot 0 \%)$, and vomiting $(41 \cdot 7 \%)$. Generally patients were still experiencing their symptoms in the week before surgery, although pain, nausea, and vomiting had abated for about $10 \%$. The surgeons' reports of the patients' symptoms were similar to those obtained directly from the patients.

Only $10 \cdot 8 \%$ of patients rated their general health over the previous two weeks as having been excellent or very good (Table II). In contrast, $59 \cdot 7 \%$ rated their health as only fair or poor.

Many patients reported that their present state of health was causing problems with one or more daily activities: enjoyment of food $65.4 \%$; looking after the home $52.6 \%$; sleeping $50.6 \%$; social life $42.2 \%$; home life and holidays $37 \cdot 9 \%$; interests $35 \cdot 3 \%$; job of work $26 \cdot 8 \%$; and sex life $23 \cdot 1 \%$. The last two may underestimate the problem as an unknown proportion of patients will not have been in paid employment or sexually active.

\section{CHANGE IN SYMPTOMS AND HEALTH STATUS} AFTER SURGERY

After surgery $42 \cdot 8 \%$ of patients reported they were symptom free, $35.6 \%$ reported one symptom present, $12 \cdot 6 \%$ two symptoms, $7 \cdot 8 \%$ three symptoms, and $1 \cdot 2 \%$ four or more symptoms. The proportion of patients with each symptom after surgery ('remain unwell' and 'worse') varied from $0.4 \%$ reporting jaundice, $3.2 \%$ vomiting, and $4.1 \%$ fever to $23.5 \%$ reporting abdominal pain and $28 \cdot 1 \%$ flatulence (Fig 1, based on 468 patients who answered the symptom questions both before and after surgery).

The effect of surgery on symptoms can also be assessed by the proportion of those suffering from each symptom before surgery who reported an improvement afterwards. This varied from $96.6 \%$ for jaundice, $89.4 \%$ for vomiting, $80.6 \%$ for nausea, and $79.2 \%$ for fever to $68.5 \%$ for loss of appetite, $64.9 \%$ for abdominal pain, and only $50.7 \%$ for flatulence. The surgeons' reports of postoperative abdominal pain $(20.7 \%$ mild and $1 \cdot 2 \%$ severe pain) were similar to reports obtained directly from the patients $(23.5 \%)$. The same was true for reports of jaundice (surgeons $0 \cdot 2 \%$, patients $0.4 \%$ ).

Improvements in symptoms are reflected in patients' reports of their general health (Table II). One hundred and forty six $(31 \cdot 7 \%)$ reported improving by at least two points on the five point scale, $143(31.0 \%)$ improved by one point, $129(28 \%)$ were unchanged, and $43(9 \cdot 3 \%)$ reported feeling worse. The proportion of patients who improved from poor/fair beforehand $(69.7 \%)$ to good/very good/excellent afterwards $(79.4 \%)$ was $41 \%(\mathrm{CIs}=34$ to $48 \%$; $<0.0001)$. 


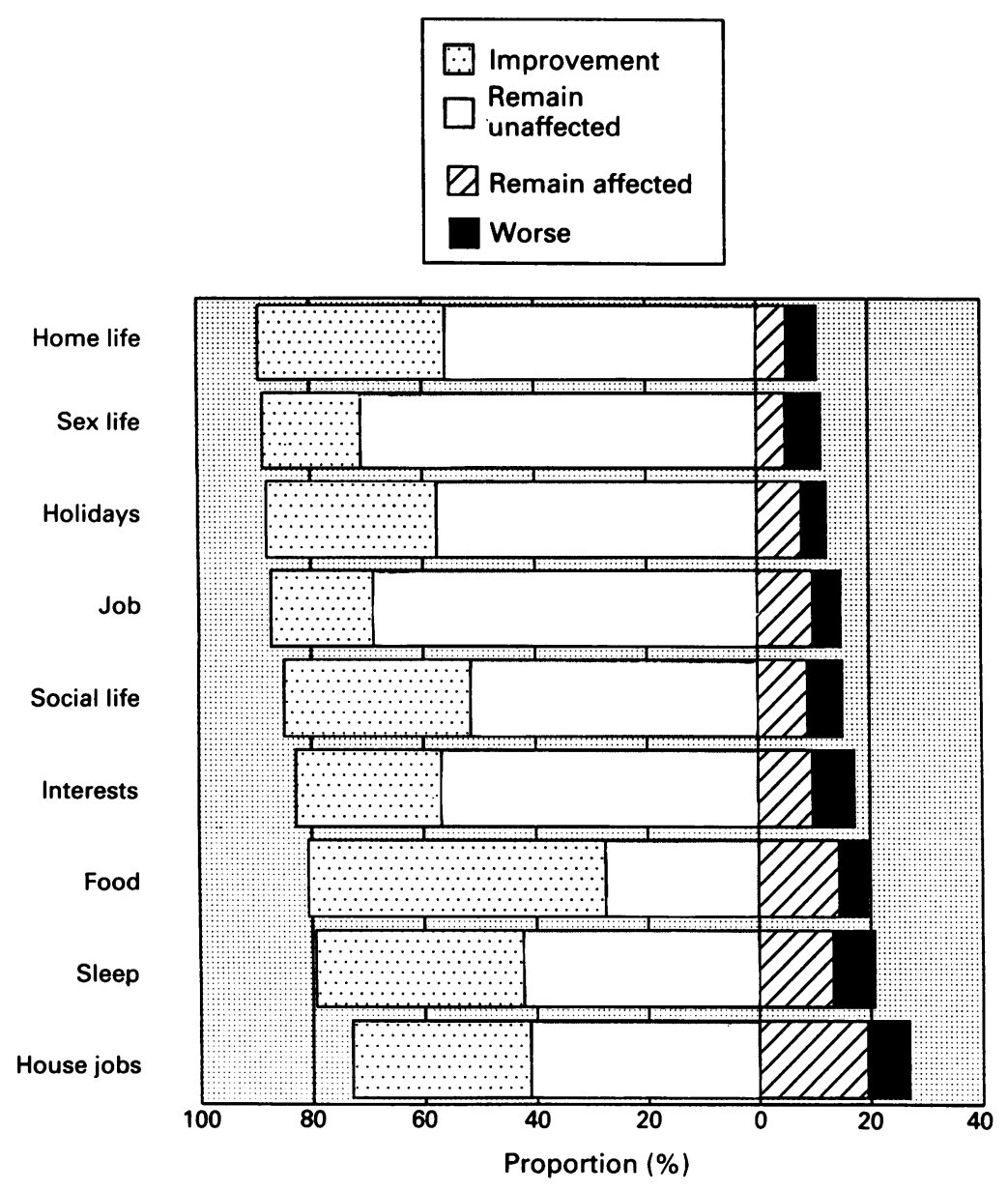

Figure 2: Proportions of patients reporting improvement, remaining unaffected, remaining affected, and worsening of ability to carry out activities $(n=468)$.

After surgery over half the patients $(52 \cdot 3 \%)$ reported that their state of health did not cause problems with any of nine social activities. Fourteen per cent reported problems with one activity, $9 \cdot 5 \%$ with two, $5 \cdot 3 \%$ with three, and $18.9 \%$ with four or more. The impact of surgery varied slightly between activities (Fig 2). Of those with some limitation of their activity before surgery, the proportion reporting no such limitation afterwards was similar for all nine activities, only varying from $54-75 \%$.

The speed of postoperative recovery was assessed by the length of time patients reported they spent (after leaving hospital) resting in bed, in their home, and before returning to work (Table III). Half the patients spent some time resting in bed when they got home but only $6 \cdot 1 \%$ spent more than 10 days. Most people waited about one to two weeks before venturing outside their homes though for some $(8 \cdot 4 \%)$ it was over four weeks before they went
TABLE IV Patients' expectations of the outcome of surgery $(n=583)$

\begin{tabular}{lc}
\hline & No (\%) \\
\hline Without surgery: & \\
My symptoms would continue & $219(37 \cdot 6)$ \\
My symptoms would get worse & $443(76 \cdot 0)$ \\
I would not live as long & $197(33 \cdot 8)$ \\
My liver would be damaged & $309(53 \cdot 0)$ \\
I don't know what would happen & $186(31 \cdot 9)$ \\
Surgery will improve my life: & $214(36 \cdot 7)$ \\
Very much & $273(46 \cdot 8)$ \\
Quite a lot & $74(12 \cdot 7)$ \\
A little & $12(2 \cdot 1)$ \\
Not at all & $120(21 \cdot 0)$ \\
Extent of preoperative worry about surgery: & $255(44 \cdot 7)$ \\
Not at all & $102(17 \cdot 9)$ \\
A little worried & $94(16 \cdot 5)$ \\
Quite worried & \\
Very worried &
\end{tabular}

out. There was no significant difference in the speed of recovery between people aged under 65 and those 65 and older. Of those in paid employment, almost $60 \%$ returned to work within four weeks. There was a modest increase in the use of some domiciliary services after surgery compared with beforehand. The proportion receiving home help increased from 5 to $8 \%$, district nurse visits 3 to $7 \%$, meals on wheels 1 to $2 \%$, bath attendant 1 to $4 \%$, and laundry services 3 to $9 \%$. There was no change in the proportion using day centres $(18 \%)$.

PATIENTS EXPECTATIONS AND SATISFACTION Patients generally had high expectations about the benefits of surgery (Table IV). Without surgery, many felt their symptoms would continue $(37 \cdot 6 \%)$ or get worse $(76 \%)$ and a third thought they would not live as long. Conversely, most $(83.5 \%)$ expected either quite a lot or much improvement in their lives. People varied considerably as regards how worried they were about their operation. A significant proportion $(34.4 \%)$ were either quite or very worried.

After surgery, most patients expressed satisfaction (Table V). Most $(87 \cdot 3 \%)$ felt they had received sufficient information beforehand, their recovery had been as fast or faster than expected $(77 \cdot 3 \%)$, and the results as good or better than expected $(89 \cdot 5 \%)$.

\section{Discussion}

Despite the obvious difficulties of carrying out a questionnaire based cohort study in eight countries, 583 patients were successfully recruited and information about their outcome was obtained from their surgeons $(96 \%)$ and from most patients $(83 \%)$. No serious responder bias was detected.

TABLE III Number of days spent (because recovering from operation) resting in bed, at home, and off work after leaving hospital by age $(n=486)$

\begin{tabular}{|c|c|c|c|c|c|c|c|}
\hline & \multirow[b]{2}{*}{ Age } & \multicolumn{6}{|l|}{ Days } \\
\hline & & None & $1-5$ & $6-10$ & $11-17$ & $18-31$ & 32 Or more \\
\hline $\begin{array}{l}\text { Days spent staying in bed all } \\
\text { or most of the day } \\
\text { Days spent staying in and } \\
\text { around the house } \\
\text { Days spent staying off work } \\
\text { (if in paid employment) }\end{array}$ & $\begin{array}{c}<65 \\
65+ \\
<65 \\
65+ \\
<65\end{array}$ & $\begin{array}{r}163(47 \cdot 2) \\
64(45 \cdot 4) \\
35(10 \cdot 3) \\
17(12 \cdot 3) \\
6(3 \cdot 5)\end{array}$ & $\begin{array}{c}102(29 \cdot 6) \\
40(28 \cdot 4) \\
63(18 \cdot 5) \\
13(9 \cdot 4) \\
2(1 \cdot 2)\end{array}$ & $\begin{array}{l}62(18 \cdot 0) \\
25(17 \cdot 7) \\
78(22 \cdot 9) \\
36(26 \cdot 1) \\
13(7 \cdot 6)\end{array}$ & $\begin{array}{c}12(3 \cdot 5) \\
8(5 \cdot 7) \\
76(22 \cdot 4) \\
35(25 \cdot 4) \\
12(7 \cdot 1)\end{array}$ & $\begin{array}{c}6(1 \cdot 7) \\
4(2 \cdot 8) \\
59(17 \cdot 4) \\
26(18 \cdot 8) \\
66(38 \cdot 8)\end{array}$ & $\begin{array}{c}0(-) \\
0(-) \\
29(8 \cdot 5) \\
11(8 \cdot 0) \\
71(41 \cdot 8)\end{array}$ \\
\hline
\end{tabular}

Differences between age groups not significant at $5 \%$ value. 
TABLE V Patient satisfaction with the process and outcome of surgery $(n=486)$

\begin{tabular}{lc}
\hline & $N o(\%)$ \\
\hline Information received before surgery was: & \\
Insufficient & $56(11 \cdot 5)$ \\
Sufficient & $376(77 \cdot 4)$ \\
Too much & $48(9 \cdot 9)$ \\
Recovery from surgery has been: & $104(21 \cdot 4)$ \\
Slower than expected & $184(37 \cdot 9)$ \\
About as expected & $191(39 \cdot 3)$ \\
Faster than expected & $45(9 \cdot 3)$ \\
Results of the operation have been: & $207(42 \cdot 6)$ \\
Worse than expected & $228(46 \cdot 9)$ \\
About as expected & \\
Better than expected & \\
\hline
\end{tabular}

The first objective was to describe the preoperative health of the patients. Their symptom pattern varied considerably. While abdominal pain was the commonest one, it was by no means universal - $24 \%$ of patients reported suffering no pain during the six months before surgery and $40 \%$ none in the preceding week, a finding confirmed by their surgeon. Other symptoms were more variable, with only a half or less of the patients reporting them. Overall, most patients' general health was poor or only fair and this was reflected in the wide variety of aspects of their lives that were adversely affected, most notably their enjoyment of food.

Clearly conditions other than their gall bladder disease could have been contributing to such adversities, which cholecystectomy would not be expected to alleviate.

The second objective sought to describe any changes in symptoms and health status after surgery. Generally speaking most patients reported improvements in their health. After surgery $43 \%$ were free of all symptoms. Surgery seemed to resolve some symptoms more than others - jaundice, vomiting, nausea, and fever generally improved whereas only $65 \%$ of those with abdominal pain and $51 \%$ of those with flatulence achieved relief. As a result, about a quarter of all patients were still suffering from these two symptoms six weeks after surgery. These findings are consistent with previous reports. ${ }^{34}$

While most patients reported an improvement in their general health, many felt no improvement and a small proportion actually felt worse. This was mirrored by the impact of the operation on patients' social activities between a half and three quarters of those limited before surgery were unimpaired afterwards. An American study reported less impact ${ }^{13}$ but this might reflect a difference in thresholds for surgery - the American patients may have been suffering from less severe symptoms beforehand. This is reflected in the proportions who had returned to work within four to six weeks - only about half the European patients (similar to the findings of a British study ${ }^{12}$ ) compared with most US patients. $^{1}$
The third objective sought to describe the patients' level of satisfaction with their treatment. Generally patients were satisfied both with their care and the results. Few felt the results were worse than expected even though, as has been seen, about a quarter were still suffering from abdominal pain and flatulence. This suggests that some patients' expectations are not high.

As newer, rival treatments for gall bladder disease are introduced and adopted it is essential that their effectiveness is compared with the established treatment, open cholecystectomy. This paper provides some baseline data for such comparisons to be carried out. Other papers based on this study will provide information on the indications for surgery, complications, and comparisons between hospitals.

We would like to thank: Christine Vosper for data entry; the surgeons, nurses, and other hospital staff who collected data; and the patients for providing information. The project received and the patients for providing information. The project received fevelopment meetings. Subsequently, data collection in each hospital was financed by local sources while funds for coordination, management, and analysis were provided by the Health tion, management, and analysis were provided by the Health
Services Research Unit, London School of Hygiene and Services Research

Tropical Medicine. C Casas, O Ramis Juan (Figueres, Spain); M Motos (Sabadell, Spain); L Chambaud (Rennes, France); C Gerges, F Rannau (Quimper, France); J P Robinson, P V Delaney, M Keshtgar (Limerick, Ireland); G Watson (Waterford, Ireland); E Christofiori, M Costa, V Valsecchi (Lecco, Italy); A Pauda de Carvalho, C Pipa, T Passos (Viana do Castelo, Portugal); Carvalho, C Pipa, T Passos (Viana do Castelo, Portugal); L Johansen (Lidkoping, Sweden); T Bosch, P Smits (Almelo, Netherlands); H Brand (Minden, Germany); J Postlethwaite Netherlands); H Brand (Minden, Germany);
(Barnet, UK); D J W Hunter (London, UK).

1 Johnston DE, Kaplan MM. Pathogenesis and treatment of gallstones. N Engl f Med 1993; 328: 412-21.

2 US National Institutes of Health. Consensus Development Conference Statement on Gallstones and Laparoscopic Cholecystectomy. Am ₹ Surg 1993; 165: 390-6.

3 Bodvall B, Overgaard B. Computer analysis of postcholecystectomy biliary tract symptoms. Surg Gynecol Obstet cystectomy biliary

4 Burnett W, Shields R. Symptoms after cholecystectomy. Lancet 1958; i: 923-5.

5 Gilliland TM, Trverso LW. Modern standards for comparison of cholecystectomy with alternative treatments for symptomatic cholelithiasis with emphasis on long term relief of symptoms. Surg Gynecol Obstet 1990; 170: 39-44.

6 Ros E, Zambon D. Postcholecystectomy symptoms. A prospective study of gall stone patients before and two years after surgery. Gut 1987; 28: 1500-4.

7 Bardsley MJ. A study of patient outcomes in an acute hospital [Dissertation]. London: University of London, 1991.

8 Nicholl JP, Brazier JE, Milner PC, et al. Randomised controlled trial of cost-effectiveness of lithotripsy and open cholecystectomy as treatments for gallbladder stones. cholecystectomy as trea

9 Bardsley MJ, Venables CW, Watson J, et al. Evidence for validity of a health status measure in assessing short term outcomes of cholecystectomy. Quality in Health Care $1992 ; 1: 10-4$.

10 Barkun JS, Barkun AN, Sampalis JS. Randomised controlled trial of laparoscopic versus mini cholecystectomy. Lancet 1992; 340: 1116-9.

11 Mitchell JH, Hardacre JM, Wenzel FJ, Lohrenz FN. Cholecystectomy peer review: measurement of four variables. Med Care 1975; 13: 409-16.

12 Bates T, Mercer JC, Harrison M. Symptomatic gall stone disease: before and after cholecystectomy. Gut 1984; 25: A579-80.

13 Cleary PD, Greenfield S, Mulley AG, et al. Variations in length of stay and outcomes for six medical and surgical length of stay and outcomes for six medical and surgical 265: 73-9.

14 Sanderson CFB, Bosch T, Goosen J, et al. Reviewing the process and outcome of hospital care in Europe: the tracer method. International fournal of Health Planning and Management 1987; 2: 293-9. 